\title{
A Methodology for the Zoning Danger Region in Small Arm Firing Range Using Aerial Photogrammetry with Drone
}

\author{
Jang-Woon Baek (iD, Chang-Su Jang, and Young-Jun Park \\ Department of Civil Engineering and Environmental Sciences, Korea Military Academy, 01805 Seoul, Republic of Korea \\ Correspondence should be addressed to Young-Jun Park; parky@mnd.go.kr
}

Received 19 March 2020; Revised 13 May 2020; Accepted 27 May 2020; Published 16 June 2020

Academic Editor: Jinyang Xu

Copyright (C) 2020 Jang-Woon Baek et al. This is an open access article distributed under the Creative Commons Attribution License, which permits unrestricted use, distribution, and reproduction in any medium, provided the original work is properly cited.

\begin{abstract}
During firing exercises in the military forces, safety accidents have occurred and caused nonbattle loss of human lives. Despite huge impact of the safety accidents in firing ranges on the military forces and civilians, the preventive measures have been limited and inflexible. In this study, to decrease the accident rate in small arm firing ranges, a methodology was presented to determine danger zones in firing ranges that resulted from direct bullets or ricochets during firing exercises. On the basis of ballistic theory and the actual terrain data surveyed by a drone, the danger zone of OO Firing Range was identified by schematizing the trajectories of the direct bullets and ricochets. The Monte Carlo simulation (MCS) with the accuracy of the small arm on the terrain data showed that the danger zone of the current firing range was limited due to topographic advantages. However, when human errors were included in the MCS, the danger zones were significantly enlarged. The methodology of the present study can provide a safety check-up model that identifies danger zones in the firing ranges used by the Army.
\end{abstract}

\section{Introduction}

Firing exercise is a core element in mastering combat skill and maintaining combat power of military forces. However, the Army is experiencing much difficulty in firing exercise due to the limited number of firing ranges and civil complaints raised by residents in the vicinity of firing ranges. Particularly, as accidents in firing ranges are extremely fatal, there is a high likelihood for casualties to occur. If a safety accident occurs in a firing range, not only much effort and budget should be paid to investigate the accident and arrange countermeasures but also it deteriorates impact on morale and combat power of military forces. Such safety accidents in firing ranges are potential detonators in the military forces of the countries all over the world and are caused by diverse factors such as structural problems of firing ranges, defects of firearms and ammunition, and human mistakes.

Typical examples of safety accidents in firing ranges in Korea include a case where a stray bullet killed a soldier who was returning to the barrack after completing the work of building a fort in the 00th division in 2017 [1]. The firing range of the 00th division had an upward-looking firing line; the ground level of the firing point was lower than that of the target point, which was not able to prevent the bullet from flying over the firing range caused by a small human error. In the UK, a soldier in a safety zone of Castlemartin Firing Range was killed by a machine gun stray bullet in 2012 [2]. In the same firing range, two soldiers were killed and two soldiers were heavily wounded during live firing maneuver in 2017 [3]. In Alaska in the US, a soldier was killed during live firing maneuver in 2019 [4]. In 2018, a ricochet fell on a private house by an accident in the training area of Rodriguez Live Fire Complex possessed by the US Armed Forces in Korea [5]. This accident completely prohibited the training, and Korea and the US had to verify and improve the safety of the facility by costing a budget of 12 million US dollar [5].

The percentages of the accidents related to gun fire among the accidents involving casualties annually occurring in Australian Armed Forces were found to be $37.3 \%$ and $41.1 \%$ for active and reserve troops [6], respectively, which 
represents the fatality of accidents during a firing exercise in comparison to those during other exercises.

It is important to improve marksmanship of each solider to prevent such safety accidents in firing ranges. On the other hand, structural defects of existing firing ranges should be detected to prevent nonbattle loss and protect precious human lives. However, the previous measures taken against safety accidents in firing ranges of Korean Armed Forces were limited and inflexible, that is, simply removing those targets or closing the firing range when the safety accidents occurred. Thus, for each firing range, it is necessary to identify the safety zones (or danger zones) based on engineering methodology and to take measures to prevent those potential accidents according to the results of the analysis.

In Standard for Installation of Training Center [7] to set up danger zones in small arm firing ranges of the Army, the major manuals are summarized as follows: First, each firing range should ensure a sufficient space secured for safety, and targets should be installed avoiding rocky areas. Second, stones shall be removed from firing lines and targets, and occurrence of ricochets shall be prevented by implementing a horizontal or downward firing angle. Third, a safety zone should be secured for each firing range considering occurrence of ricochets or stray bullets and characteristics of ammunition. Fourth, safety measures should be taken for each firing range: (1) by installing a barbed wire fence, (2) by putting a warning sign in the area to civilians, and (3) forming a marginal land and so on. Fifth, the firing line shall be installed with a sufficient width of about 6 meters and the firing line gradient shall be within the range of $15^{\circ}$ to $35^{\circ}$ considering the topographic condition. Sixth, protective walls or facility shall be installed around the fence and in the shelling area and protective walls and barbed wire fences shall be installed to prevent occurrence of ricochets.

Though this standard provides overall guidelines required for installation and maintenance of a firing range by echelon, location, and/or mission, it lacks clear engineering grounds for installation of safety zones and safety facilities. Furthermore, as this standard does not address geographical conditions and topographies of diverse firing facilities, there is a risk of misjudging danger zones (or safety zones) when the same standard is applied to firing ranges with different geographical conditions and topographies.

In "Establishment of Safety Standards for Firing Range by Type of Weapon and Ammunition" [8], the danger zones of small arm firing ranges can be determined in a more engineering-based approach by probabilistically estimating the trajectory of a direct bullet and that of a ricochet strayed from a target based on ballistic theory [9-12]. However, according to the ballistic theory [9-12] used in this model, the topography of the firing range has been simplified as a plane without roughness of the ground, although the angle between a direct bullet trajectory and a target is an important parameter for ricochet trajectory, which can greatly affect the result of the danger zone. Thus, this model can have a potential error caused by the disparity between the assumed plane and the topography of the firing range.

In the present study, to address the effect of actual topography of small arm firing range, numerical data of topography were used. A three-dimensional terrain model and orthophotographs were obtained through aerial photography of a firing range using a drone. Then, the Monte Carlo simulation for trajectories of direct bullets and ricochets was performed addressing the topography of the firing range. The zone subjected to occurrence of direct bullets and ricochets was schematized and determined as the danger zone; on the other hand, the zones subjected to nonoccurrence of direct bullets and ricochets were determined as the safety zones. The methodology in the present study can be applied to actual firing ranges addressing actual topography and, according to the results of the numerical analyses, safety measures can be established based on the engineering evidence to prevent safety accidents during firing exercises in small arm firing ranges of the Army.

\section{Review on Range Safety}

In the US Standard (DA PAM 385-63 Range Safety) [13], the prerequisites for setup of danger zones in small arm firing ranges are defined as follows: (1) firearms with no performance problem are used by trained personnel in accordance with the prescribed procedures and no human mistake; (2) the size and form of the danger zones vary depending on the performance and characteristics of the weapon system, ammunition, training requirements, geographical position, and environmental conditions; and (3) a Surface Danger Zone (SDZ) is defined as a space of the Earth and the air above which personnel and/or equipment may be endangered by weapons firing or demolition activities.

Based on such conditions, the US Armed Forces have set up danger zones using RMKT (Ranger Manager Toolkit), a three-dimensional GIS program used to consider topographical conditions [13]. According to the result of this study, danger zones can be divided into two different shaped small arm zones; the cone type small arm danger zones are applied during Stop Fire, whereas the bat wing type small arm danger zones are applied to the cases where risk for ricochets to occur is high in a firing exercise that includes InMotion Fire and Flanking Fire. However, the process of this study is not disclosed for the reason of security. Furthermore, as domestic topography and environment are different from those of the US, there is a limitation in applying this standard to Korean Armed Forces.

Jeon et al. [8] pointed out lack of standards for determining danger zones during a firing exercise due to direct bullets, ricochets, ammunition fragments, and so on. They schematized the danger range in an actual firing range by drawing the trajectories of direct bullets and ricochets for each small arm type to estimate the maximum danger zone considering probable error, accuracy of weapon, and terrain gradient. They also presented a trajectory analysis model that includes the bullet trajectory analysis and actual topography by comparing the standard of the Army with that of the US Armed Forces. However, as they carried out two-dimensional trajectory analysis of $X$-axis and $Z$-axis, in the moving direction and the altitude direction of the bullet, respectively, by applying only the longitudinal gradient of the firing direction and then carrying out two-dimensional trajectory 
analysis of $X$-axis and $Y$-axis again using the weapon error and standard deviation, there is a limitation in determining the danger zones considering the three-dimensional topography of the actual firing range.

Accordingly, in the present study, high-resolution numerical terrain data were obtained using an aerial photogrammetry by drone. Using the numerical terrain data and calculation of trajectories of direct bullet sand ricochets, the danger zones of the firing range addressing the actual threedimensional topography were considered. Therefore, the danger zones can be better fitted into the circumstances of the Korean Army by using domestic topography.

\section{Ballistic Trajectory Using Ballistic Theory}

To determine the danger zones of a firing range, it is required to calculate the ballistic trajectory of a bullet fired by a gun until it stops and loses all its energy. Accordingly, in the ballistic trajectory analysis during a small arm fire, the direct bullet trajectory from the muzzle to the point of impact using modified point mass analysis method was first calculated [10]. After the impact, the trajectory of a ricochet was calculated based on incidence angle with the ricochet angle $\theta_{\beta}$, drift angle $\theta_{\gamma}$, deflection angle $\theta_{z}$, and ricochet speed $V_{\text {ricochet }}$ at the impact point of the direct bullet trajectory.

3.1. Direct Bullet Ballistic Curve. In the direct bullet trajectory analysis using the modified point mass analysis method [10], it was assumed that (1) drag acts on the center of a bullet, (2) gravitational acceleration is paralleled at all times, (3) the Earth is flat and not rotate, (4) the atmosphere is standard atmosphere, which has constant temperature and density without wind, and (5) movement of bullet shall be set up on a plane of two-dimensional coordinates basically with $X$-axis and $Z$-axis.

The calculation formulas of speeds in $X$-axis and $Z$-axis directions and trajectory addressing the above assumptions can be derived as follows:

$$
\begin{aligned}
& v_{0 x}=v_{-1 x}\left(1-\frac{\rho A C_{d} \sqrt{v_{-1 x}^{2}+v_{-1 z}^{2}}}{2 m} \Delta t\right), \\
& v_{0 z}=v_{-1 z}\left(1-\frac{\rho A C_{d} \sqrt{v_{-1 x}^{2}+v_{-1 z}^{2}}}{2 m} \Delta t\right)-g \Delta t \\
& x_{0}=x_{-1}+\left(x_{-1}+x_{-2}\right)\left(1-\frac{\rho A C_{d} \sqrt{\left(x_{-1}-x_{-2}\right)^{2}+\left(z_{-1}-z_{-2}\right)^{2}}}{2 m}\right), \\
& z_{0}=z_{-1}+\left(z_{-1}+z_{-2}\right)\left(1-\frac{\rho A C_{d} \sqrt{\left(x_{-1}-x_{-2}\right)^{2}+\left(z_{-1}-z_{-2}\right)^{2}}}{2 m}\right)-g \Delta t^{2},
\end{aligned}
$$

where $t_{d}=$ unit time (sufficiently small time interval value, 0.05 seconds or shorter), $\rho=$ air density (a dependent variable of air temperature and atmospheric pressure), $A=$ cross section area of bullet $\left((\pi / 2) d^{2}\right.$, when diameter is d), $C_{d}=$ drag coefficient, $g=$ gravitational acceleration $\left(\approx 9.8 \mathrm{~m} / \mathrm{s}^{2}\right), x_{0}, z_{0}=$ current position values of $X$-axis and $Z$ axis, respectively, $x_{-1}, z_{-1}=$ position values of $X$-axis and $Z$ axis at the previous unit time, respectively, $x_{-2}, z_{-2}=$ position values at the unit time previous to $x_{-1}, z_{-1}$, respectively, $v_{0 x}, v_{0 z}=$ current position speed of $X$ axis and $Z$-axis, respectively, and $v_{-1 x}, v_{-1 z}=$ position speed of $X$-axis and $Z$-axis at unit time previous to the current position.

3.2. Ricochet Ballistic Curve. After a direct bullet hits the ground, it flies again using the residual energy. The trajectory of a ricochet can be predicted using ricochet angle $\theta_{\beta}$, drift angle $\theta_{\gamma}$, deflection angle $\theta_{z}$, and ricochet speed $V_{\text {ricochet }}$, which result from incidence angle $\theta_{\alpha}$, critical angle $\theta_{c}$, bullet rotating speed $R_{s}$, and ground inclination angle in the transverse direction $\theta_{g t}$ [8] (Figure 1).

In Figure 1(a), a direct bullet arrives at point $\mathrm{A}$ at an incidence angle with the ground $\theta_{\alpha}$ and the bullet departs the ground surface at point $\mathrm{B}$ at a ricochet angle $\theta_{\beta}$ with the ground surface. The ricochet angle $\theta_{\beta}$ varies depending on the physical properties of the bullet and point of impact. In the present study, the impact surface is assumed to be made of sand. The ricochet angle $\theta_{\beta}$ is solely a function of the bullet incidence angle $\theta_{\alpha}$, which can be obtained for the sand ground using the following existing empirical formula [8]:

$$
\theta_{\beta}=0.0315 \times \theta_{\alpha}^{2}+0.0334 \times \theta_{\alpha}+7.616+\theta_{\alpha} .
$$

On the other hand, the ricochet also turns the way in the transverse direction at a drift angle with moving direction $\theta_{\gamma}$ (Figure $1(\mathrm{~b})$ ). The drift angle $\theta_{\gamma}$ depends on a weapon rifling and bullet rotating speed $R_{s}(\mathrm{rad} / \mathrm{s})$ and, at the same $R_{s}, \theta_{\gamma}$ is proportional to the incidence angle $\theta_{\alpha}$, 


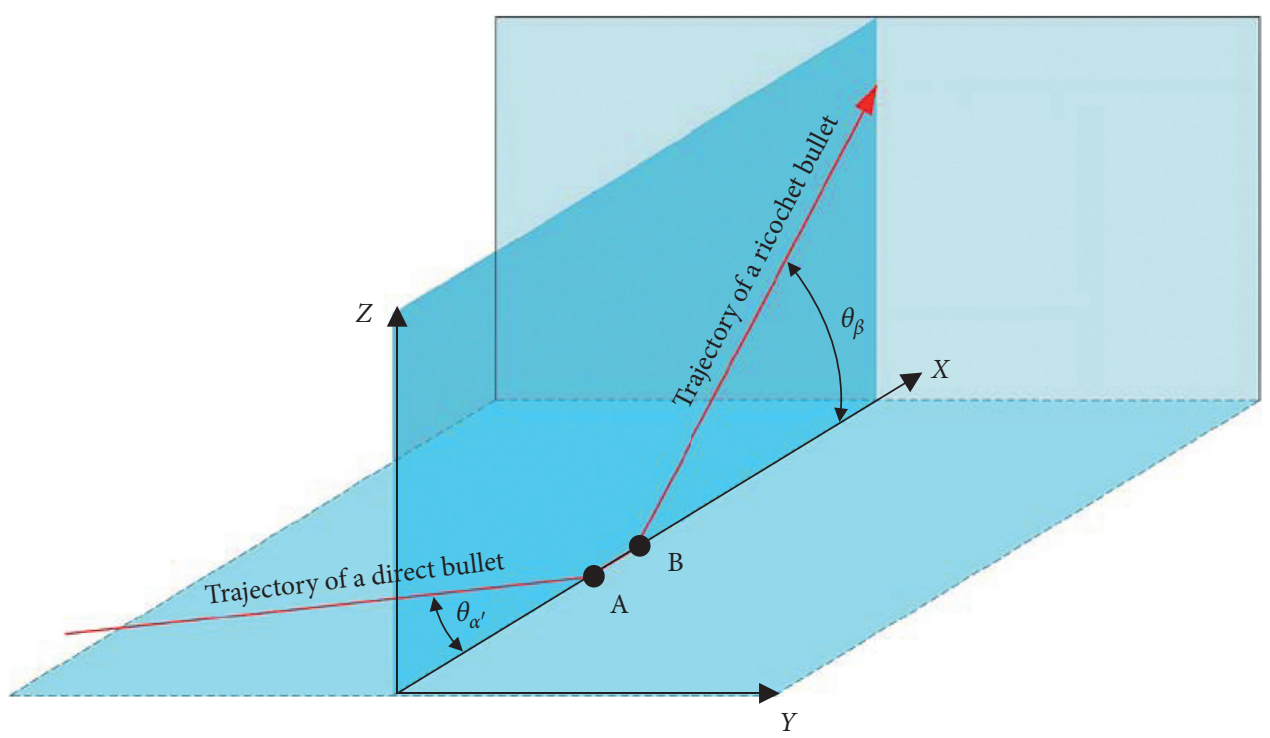

(a)

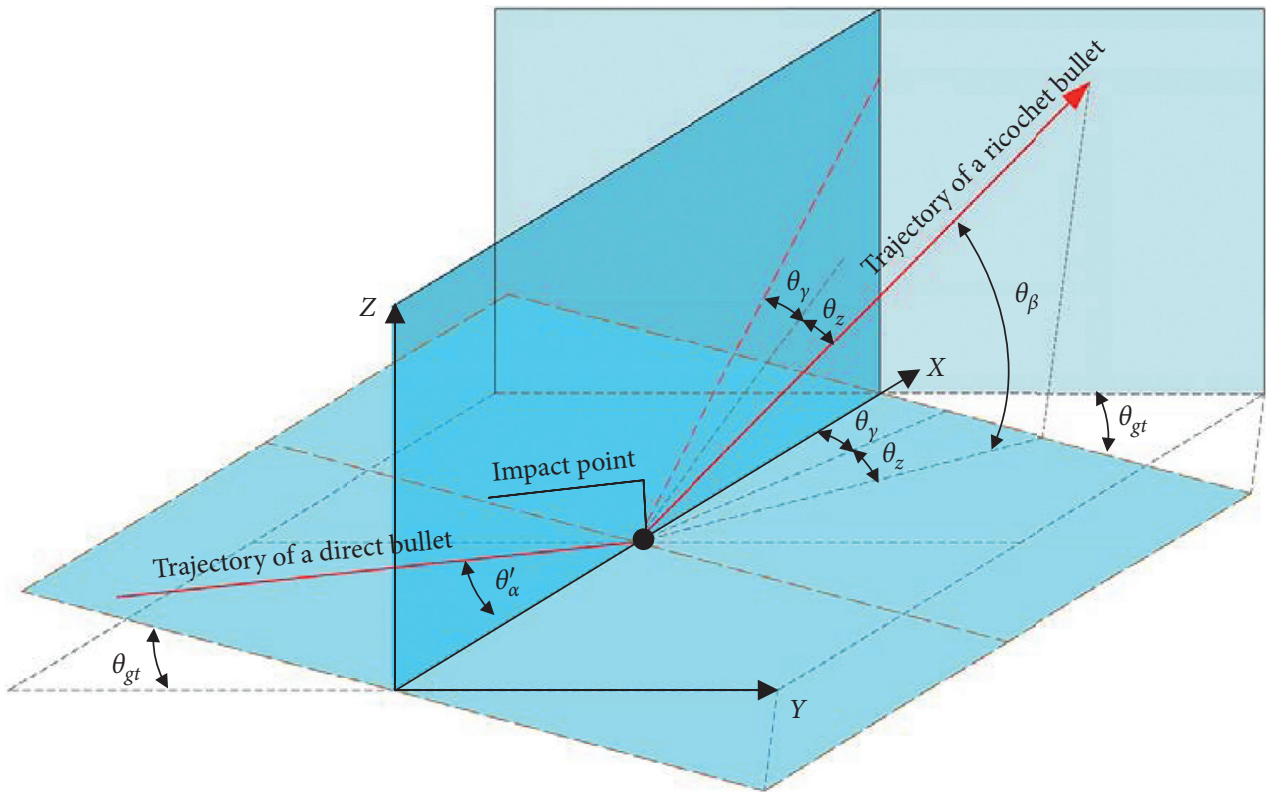

(b)

Figure 1: Components for calculation of a ricochet's trajectory. (a) Terrain without ground inclination. (b) Terrain with ground inclination angle in the transverse direction $\theta_{g t}$.

regardless of the bullet speed and properties of the ground. Thus, the drift angle $\theta_{\gamma}$ can be obtained using the following equation [8]:

$$
\theta_{\gamma}=0.0883 \times \theta_{\alpha}+\frac{R_{s}}{800}+1.2395
$$

As the bullet penetrates into the ground and breaks through the ground after traveling a certain length depending on the impact specification of the bullet and the characteristics of the impact surface (Figure 1(a)), the point of impact generally does not match with the starting point of the ricochet. However, such an error is considered negligible in determining firing safety range. Thus, for simplicity, the starting point of the ricochet was assumed to be the same as the point of impact (Figure 1(b)).

In case the ground is inclined at an inclination angle in the transverse direction $\theta_{g t}$, perpendicular to the moving direction of the bullet (Figure 1(b)), the ricochet turns the way more in the transverse direction at a deflection angle $\theta_{z}$ with the moving direction. In Figure 2, for each transverse inclination angle $\theta_{g t}$ between $0^{\circ}$ and $85^{\circ}$, the range $X$ and deflection $Z$ are calculated and drawn. Using the slope between the origin and the arrival points of the ricochet (i.e., $\theta_{z}=X / Z$ ), the deflection angle $\theta_{z}$ can be expressed as a function of transverse inclination angle $\theta_{g t}$ at the impact surface (Figure 3). In the previous study [8], 


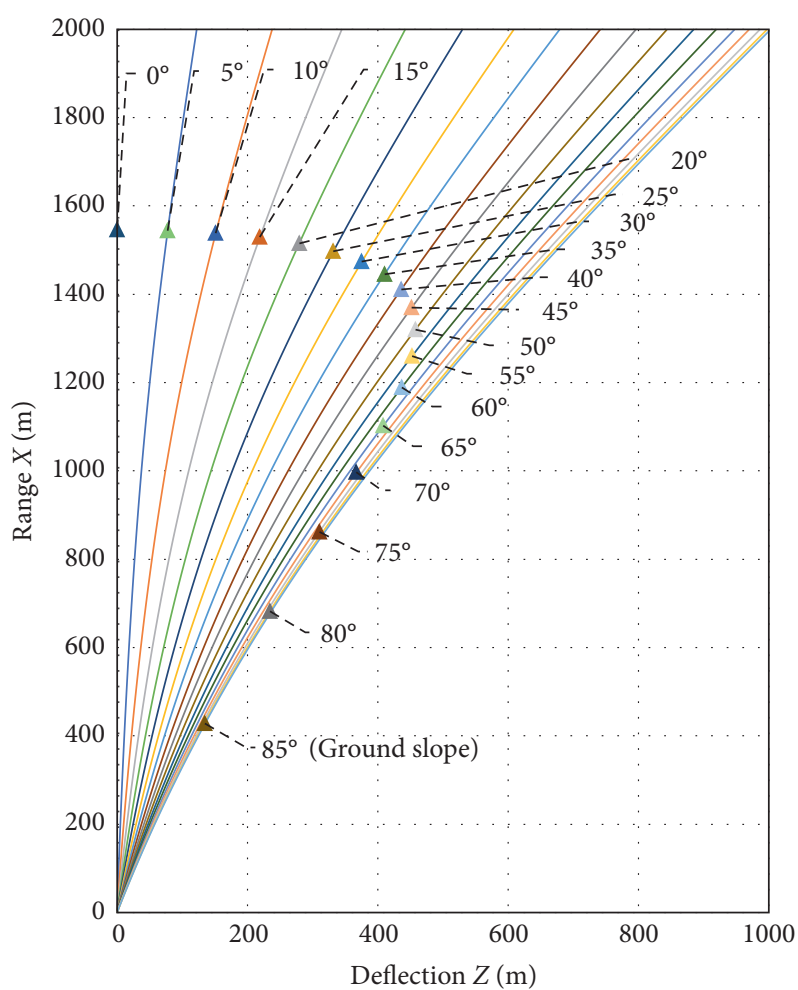

FIgUre 2: Relationships of range and deflection using K2 Rifle and K100 Bullet.

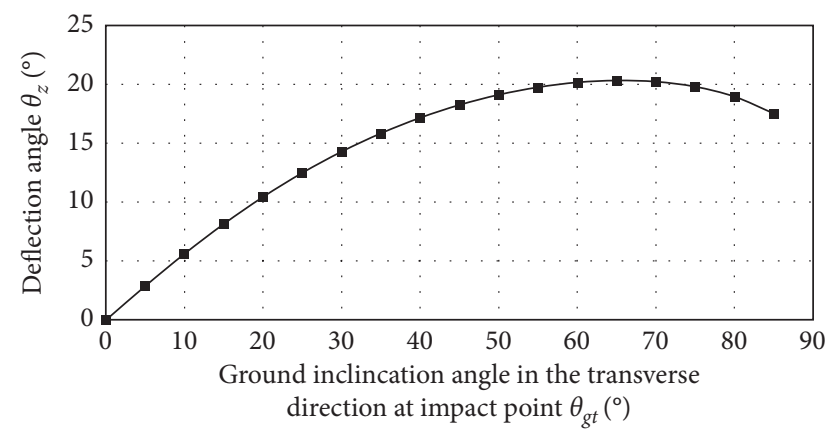

FIGURE 3: Deflection angle varied with ground inclination angle in the transverse direction at impact point.

the deflection angle $\theta_{z}$ was derived through a regression analysis as follows:

$$
\begin{aligned}
\theta_{z}= & \left(-9 \times 10^{-6} \times\left|\theta_{g t}\right|^{3}\right)-\left(0.0037 \times\left|\theta_{g t}\right|^{2}\right) \\
& +\left(0.5944 \times\left|\theta_{g t}\right|\right)+0.0509 .
\end{aligned}
$$

On the other hand, when there is an inclination angle in the longitudinal direction $\theta_{g l}$, paralleled to the moving direction (Figure 4$), \theta_{g l}$ is simply added to the incidence angle with a horizontal plane $\theta_{\alpha}^{\prime}$ (i.e., $\theta_{\alpha}^{\prime}=$ the incidence angle when $\theta_{g l}=0$ ). Thus, due to $\theta_{g l}$, the incidence angle $\theta_{\alpha}$ is increased as much as $\theta_{g l}$; that is, $\theta_{\alpha}=\theta_{\alpha}^{\prime}+\theta_{g l}$.

After the direction of the ricochet is determined, the ricochet flies with the ricochet speed $V_{\text {ricochet }}$. The ricochet speed $V_{\text {ricochet }}$ may vary depending on the incidence angle $\theta_{\alpha}$ and material properties of the impact ground. However, assuming no effect of impact surface type on $V_{\text {ricochet }}$, a simplified formula known as Birkhoff Equation [12] was used in the present study:

$$
V_{\text {ricochet }}=\left[1-\frac{\theta_{\alpha}}{2 \theta_{c}}\right] V_{\text {impact }},
$$

where the critical angle $\theta_{c}=$ the incidence angle at which no ricochet occurs due to the penetration or failure of the direct bullet, $V_{\text {impact }}=$ the bullet speed when a direct bullet hits an impact point. The critical angle $\theta_{c}$ varies depending on physical and geometrical properties of bullet and impact surface. Although the critical angle $\theta_{c}$ can be calculated from the previous study [9], for sand terrain in the present study, $\theta_{c}=15^{\circ}$ was simply used, because the ricochet speed rapidly decreases for $\theta_{c} \geq 15^{\circ}$ [8], which results in unconservative danger zones.

\section{Terrain Analysis Using Aerial Photogrammetry by Drone}

4.1. Aerial Photogrammetry by Drone. In the present study, a three-dimensional terrain model, a DSM (Digital Surface Model) and orthophotographs were acquired through aerial photography of OO Firing Range using an entry-level commercial drone, DJI Phantom3 Advance equipped with a GPS/IMU sensor [14]. The aerial photogrammetry by drone was obtained in the order of firing plan establishment, aerial photography by drone, ground control point survey, camera certification, aerotriangulation, and image matching. Under 


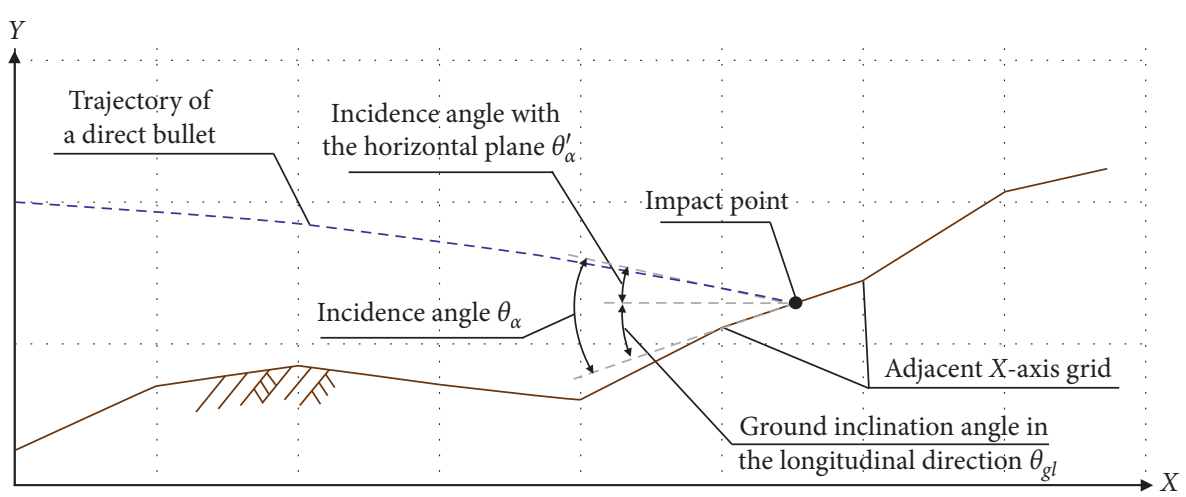

Figure 4: Calculation of incidence angle at the point of impact.

the Aviation Act, the flying altitude was allowed up to $150 \mathrm{~m}$ for the drone. The object area was photographed using Pix4D Capture program [15], which is a smartphone application for automatic flight and photographing. Using this application, once the information about the vehicle, flying altitude $(50 \mathrm{~m}$ or $120 \mathrm{~m}$ ), photographing range (whole area of OO Firing Range), and the longitudinal overlapping rate of $80 \%$ and transversal overlapping rate of $80 \%$ was input into the Pix4D Capture program and the flight path was automatically set up. As a result, 721 aerial photographs were acquired.

4.2. Ground Control Point Survey. Before performing aerial photography using an unmanned aerial vehicle (UAV), 6 internal ground control points (GCPs) in the firing range evenly distributed over the object area and 3 accessible external GCPs were selected to improve the positional accuracy of the aerial photographs acquired through the drone (Table 1). The average value of the measurements at each measurement point for 5 minutes using the virtual reference station (VRS) survey method was calculated. The GCPs are the reference points to be used for orientation work by the geometric method to produce a three-dimensional model identical to the model on the ground. The coordinates of the 9 GCPs measured were obtained using GRS80 ellipsoid and the transverse Mercator (TM) projection method.

4.3. High-Resolution Numerical Terrain Data. The 721 photographs acquired using a drone contained information of camera, photograph, and position in the exchangeable image file format (EXIF) data. Once the acquired photograph data were retrieved to Pix4D Mapper pro [16], the data are automatically aligned based on the positional information (UTM coordinate system) in the EXIF data. In the present study, the coordinate system was set up with the GRS80 ellipsoid and the TM projection method, which were used at the time of GCP survey. The UTM coordinate system, which was the attribute value of the drone photograph, was automatically converted to the coordinate system used at the time of GCP survey, and the data were aligned as shown in Figure 5.
TABle 1: Measured data of ground control points (GCPs) (in meter).

\begin{tabular}{lccc}
\hline ID of GCPs & $Y$ (north) & $X$ (east) & $Z$ (altitude) \\
\hline 1 (internal) & 563868.0 & 210595.3 & 102.841 \\
2 (internal) & 563957.2 & 210567.8 & 99.828 \\
3 (internal) & 563985.4 & 210636.2 & 104.411 \\
4 (internal) & 564062.4 & 210696.1 & 104.997 \\
5 (internal) & 564113.9 & 210714.0 & 107.419 \\
6 (internal) & 564083.3 & 210750.5 & 107.859 \\
7 (external) & 563985.7 & 210377.7 & 58.42 \\
8 (external) & 563797.1 & 211594.5 & 64.031 \\
9 (external) & 564182.7 & 211500.2 & 60.587 \\
\hline
\end{tabular}

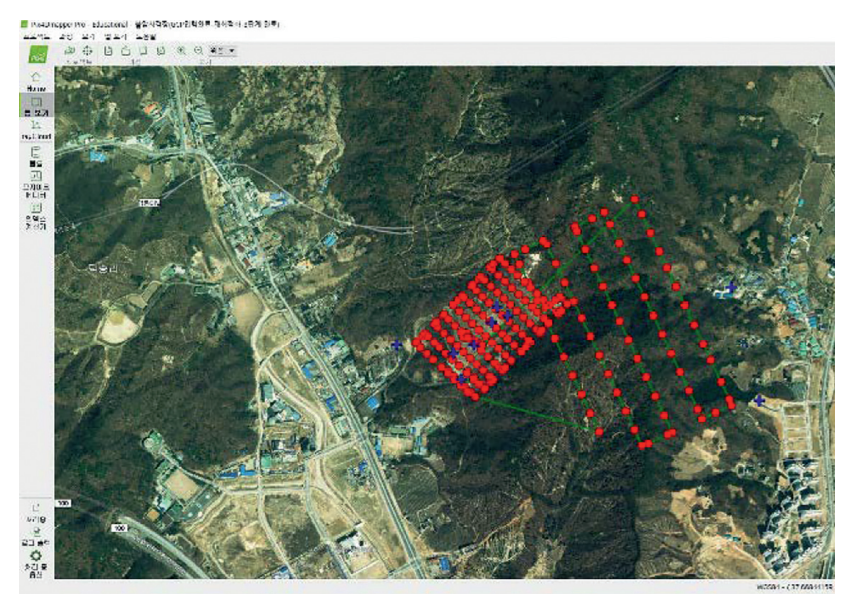

Figure 5: Uploading photos and coordinate system settings.

By initialization process after checking the aligned photographs, automatic matching was carried out by mutually recognizing the tie points with the neighboring photographs and each point cloud was formed based on the positional information of photographs. At this time, to minimize the data error, GCPs were marked on each photograph. Then, after generation of dense point clouds and a mesh work (Figure 6) of connecting each point to form a triangular net, a three-dimensional terrain model, 


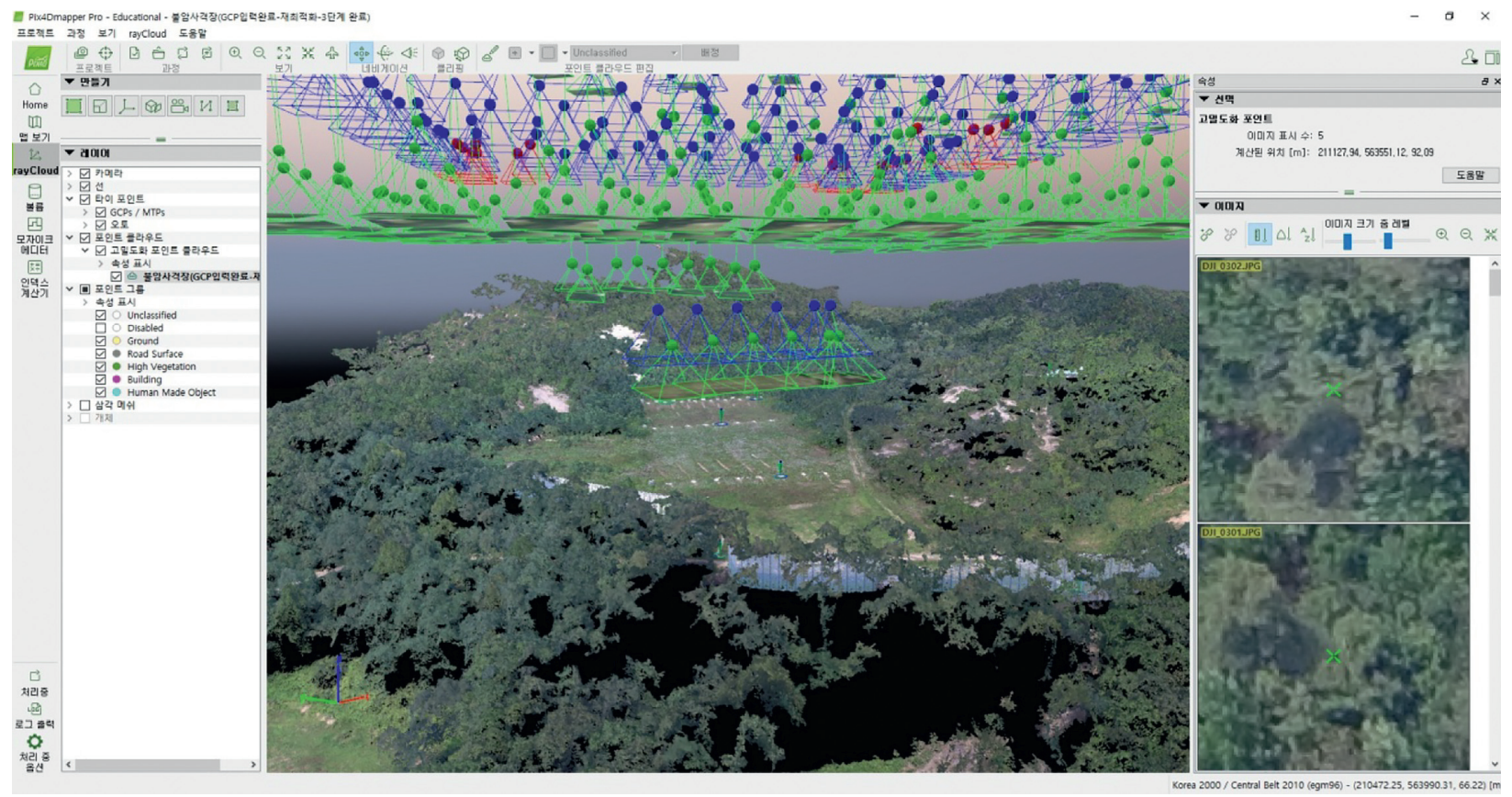

FIGURE 6: Ground control points settings and generation of dense point clouds.

orthophotographs, and DSM were created (Figure 7). To digitize the altitude value of each coordinate $(X, Y, Z)$ through the generated DSM, raster data (DSM) were converted to vector data using QGIS, which is an open-source GIS program (Table 2). In three-dimensional space coordinates, the minimum interval of width, length, and height was $1 \mathrm{~m}$. Due to such a difference in the precision, little difference exists between the vector data altitude of the DSM and the altitude of the actual terrain.

4.4. Limitations of Aerial Photogrammetry by Drone. In the process of producing a numerical terrain model through aerial photogrammetry by a drone, an error exists in reference to the actual ground level as a result of recognizing surface of trees as the terrain in this study. Furthermore, as the altitude values of $1 \mathrm{~m} \times 1 \mathrm{~m}$ grid are used, the random altitude between each grid section was determined by linear interpolation. If the change in the ground gradient is smaller than $1 \mathrm{~m}$, continuous change in ground gradient is unable to be addressed. Therefore, aerial photogrammetry utilizing an LIDAR sensor was required to distinguish trees and actual ground, and denser coordinates and altitude values are required to be applied for more accurate DSM in the further studies. Through this modification, the error can be reduced in comparison to that of the present study result.

\section{Trajectory Simulation Using Terrain Data}

5.1. Trajectory Simulation Procedure. In the present study, trajectory simulations for a direct bullet and a ricochet were performed by calculating the ballistic curves of a specific weapon in a specific terrain obtained based on aerial photogrammetry by a drone. A methodology was provided as an engineering ground for the firing range danger zones (or

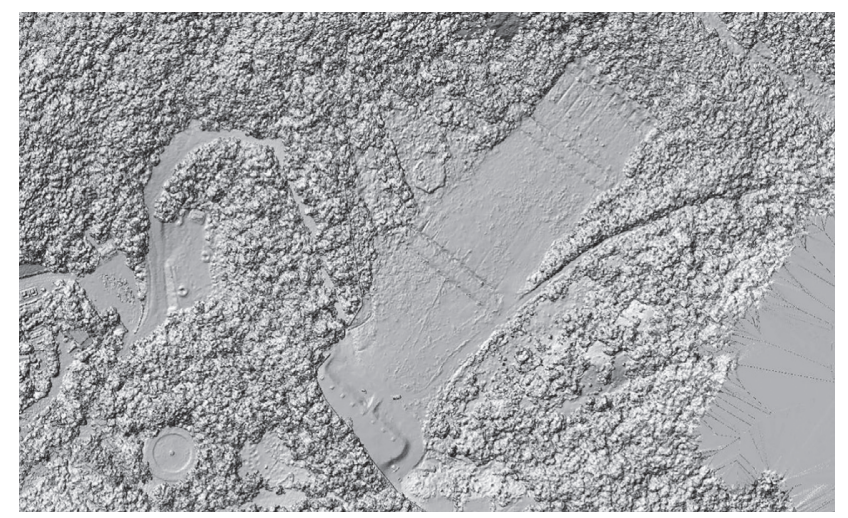

Figure 7: Generation of Digital Surface Model (DSM).

TABLe 2: Generation of vector data using QGIS (in meter).

\begin{tabular}{lcc}
\hline$X$ coordinate & $Y$ coordinate & $Z$ coordinate \\
\hline 700 & 900 & 72 \\
701 & 900 & 73 \\
702 & 900 & 72 \\
703 & 900 & 72 \\
704 & 900 & 72 \\
$\vdots$ & $\vdots$ & $\vdots$ \\
958 & 1525 & 177 \\
\hline
\end{tabular}

Note: for security reason, the entire data of OO Firing Range is not provided.

safety zones) optimized for a specific small arm firing range terrain.

5.2. Condition of Trajectory Simulation Analysis. The conditions of the trajectory simulation analysis in the present study were assumed as follows: (1) K2 rifle and K100 
ammunition were used, which are the major small arm of the Army; (2) the characteristics of small arm during trajectory analysis followed "Establishment of Safety Standard in Firing Ranges by Weapon and Ammunition Type" [8]; (3) an error was considered by minute of angle (MOA) of the small arm, where $1 \mathrm{MOA}$ is the accuracy of a weapon forming 1 inch shot group at a distance of 100 yards; (4) ricochet danger zones were determined only by primary ricochet, excluding secondary ricochets; (5) the material of all direct bullet impact surfaces was sand; and (6) an error caused by human mistakes was considered negligible in the first analysis (danger zones in firing ranges based on small arm accuracy) and was considered in the second analysis (danger zones in firing ranges based on human error).

\subsection{Initial Condition Setting. The terrain of OO Firing} Range in Korea was simulated into a three-dimensional space using aerial photogrammetry by drone. The $X, Y$, and $Z$ coordinates were between 900 and $1,525 \mathrm{~m}$, between 700 and $1,300 \mathrm{~m}$, and between 72 and $116 \mathrm{~m}$, respectively, and the interval between coordinates in each direction was $1.0 \mathrm{~m}$ (Figure 8). Assuming a prone position, the firing starting point was located at the point of $0.2 \mathrm{~m}$ above the coordinate $(1000 \mathrm{~m}, 1025 \mathrm{~m}$, and $105 \mathrm{~m})$. The specification and the initial conditions for trajectory calculation are shown in Table 3.

5.4. Trajectory Simulation of Direct Bullet. The trajectory of a direct bullet was calculated by using equations (1)-(4) from the initial conditions (Table 3). 1,000 rounds of random angles using Monte Carlo simulation (MCS) were generated such that the firing angle was in the range of $1.040^{\circ}$ to $1.202^{\circ}$, which was obtained by adding or subtracting $0.081^{\circ}$ corresponding to the weapon accuracy (4.9MOA) from the reference firing angle of $1.121^{\circ}$. The error based on the weapon accuracy was arranged to occur not only in the up/down directions (i.e., angles formed with the plane $X=1,000 \mathrm{~m}$ ) (Figure $7(\mathrm{a})$ ) but also in the right/left directions (i.e., angles formed with the plane $Y=1,025 \mathrm{~m}$ ) so that the angles are distributed over the three-dimensional coordinates (Figure 8(b)).

5.5. Trajectory Simulation of Ricochet. Using the coordinates $(X, Y$, and $Z$ ) of the impact point and the bullet speed at the time of impact, the ricochet trajectory was calculated. Because the coordinate interval of the numerical terrain data obtained through aerial photogrammetry by a drone was $1 \mathrm{~m}$, the coordinate of the impact point may not match the terrain coordinate depending on the calculation of equations (1)-(4). Thus, the coordinate of the impact point was defined as the ground coordinate closest to the point at which the ballistic curve arrived on the ground.

The incidence angle with the horizontal plane $\theta_{\alpha}^{\prime}$ (Figure 4) was calculated using an average vector passing through two coordinates: the point of impact and a bullet trajectory point immediately before the impact. The ground inclination angle in the longitudinal direction $\theta_{g l}$, paralleled to the moving direction (Figure 4), is calculated using an average vector formed by the two ground coordinates located in the front and rear of the impact point coordinate. In a similar manner, the ground inclination angle in the longitudinal direction $\theta_{g t}$, paralleled to the moving direction (Figure 1(b)), was obtained using an average vector passing through the two ground coordinates located on the left and right of the impact point coordinate. The ricochet angle $\theta_{\beta}$, drift angle $\theta_{\gamma}$, deflection angle $\theta_{z}$, and ricochet speed $V_{\text {ricochet }}$ were calculated, respectively, using equations (5)-(8) with the variables of the incidence angle $\theta_{\alpha}\left(=\theta_{\alpha}^{\prime}+\theta_{g t}\right)$ and the ground inclination angle in the longitudinal direction $\theta_{g t}$. After obtaining the initial conditions, the ballistic trajectory of ricochet was calculated through equations (1)-(4) in the same manner as that of the direct bullet (Figure $8(\mathrm{~b})$ ).

5.6. Danger Zones in Firing Ranges Based on Accuracy of Small Arm. Figure 8 shows the ballistic curve in the case where the bullet hits the target without error attributed to the weapon accuracy, whereas Figure 9 shows the ballistic curves distributed by the 4.9 MOA of the small arm when 1,000 rounds were shot using MCS. In Figure 9, due to the 4.9 MOA, the trajectory range of the direct bullet arriving at the target area was enlarged. However, the direction of the ricochet was not changed from that of ricochet without the error (comparing Figure 8 with Figure 9). The ricochet penetrated through the terrain in both cases, which indicates that bullets can be embedded in the ground without ricocheting, allowing the terrain to greatly reduce the danger zone. As a result of schematizing the danger zone range of the firing range, it was confirmed that the ricochet moved from 10 to $15 \mathrm{~m}$ to the back of the target after the direct bullet hit the impact point and did not go much beyond the lane of fire being blocked by the terrain at the point of maximum altitude of $10 \mathrm{~m}$. Therefore, as a safety measure to further reduce risk of the firing range, a $15 \mathrm{~m}$ high protective wall is required to be installed at the back of the danger zone. Furthermore, accident preventions such as installation of a fence are required to control access of personnel into the identified danger zones in the firing range.

\subsection{Danger Zones in Firing Ranges Based on Human Error.} In the previous analysis, the danger zones in firing ranges were determined based on the accuracy of the small arm. As a result, the probability for the ricochet trajectory to escape the firing range terrain was very low. However, in many firing ranges in the Army with the actual topographical condition, the rear of the firing line is not a high mountainous area differently from the result reviewed earlier. Furthermore, when danger zones of firing ranges are determined, not only the error that resulted from the accuracy of a small arm but also the error that resulted from a human error of gunners should be considered. It is difficult to quantify the error caused by a mistake of the gunners through an engineering analysis, which may be limited at the present study stage. Therefore, in this study, the error caused by a mistake of the gunner was estimated by a multiple of the 


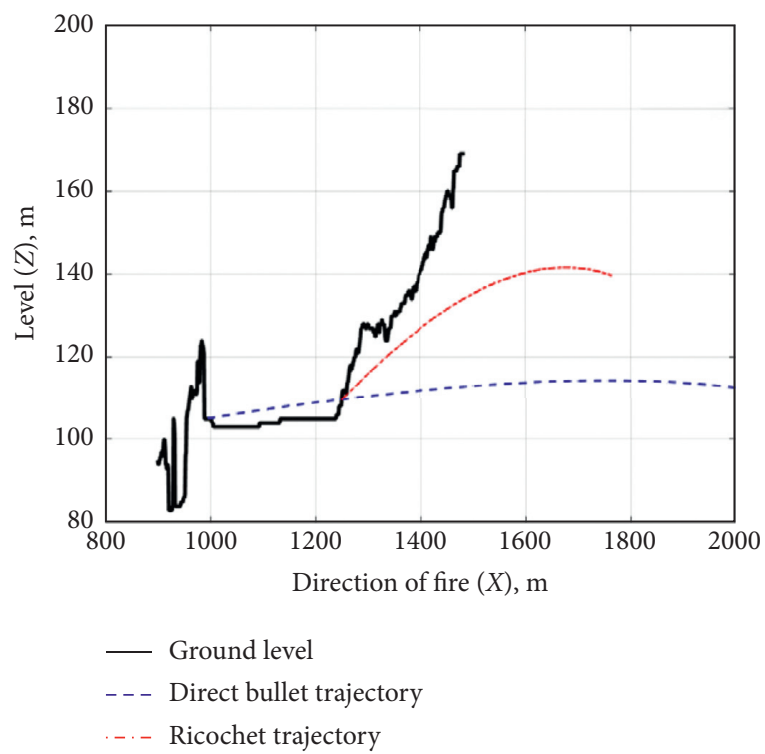

(a)

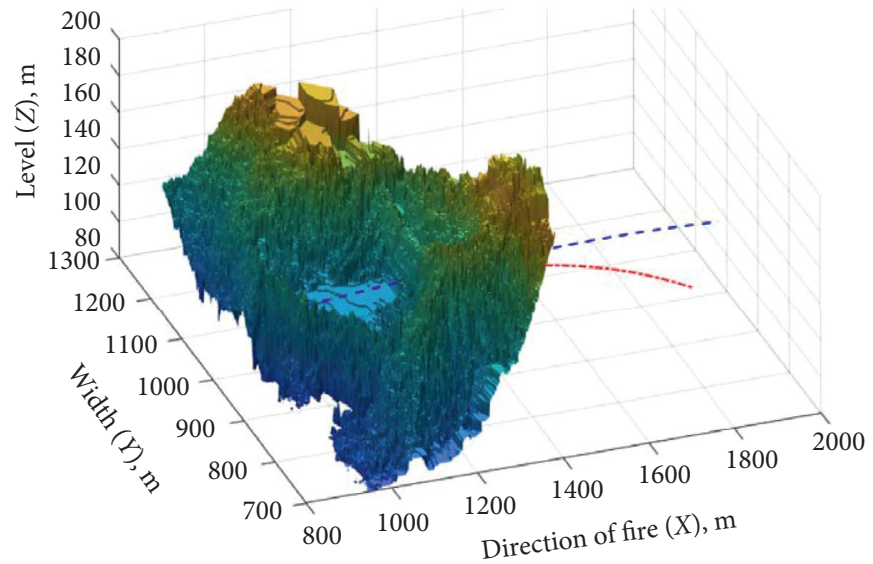

- - - Direct bullet trajectory

...- Ricochet trajectory

FIgURE 8: Bullet trajectory curves with topographic data (one fire of K2 rifle and K100 bullet without error). (a) 2D section and (b) 3D topology.

TABle 3: Initial conditions and input values for calculation of direct bullet trajectory.

\begin{tabular}{|c|c|c|}
\hline Item & Values & Remark \\
\hline Type of arm & K2 rifle & Arm name \\
\hline Accuracy & 4.9 MOA & Accuracy (angle) of an arm with a bullet \\
\hline Bullet type & K100 & Bullet name \\
\hline Length of bullet & $19.3 \mathrm{~mm}$ & The maximum length of a bullet \\
\hline Diameter of bullet & $5.56 \mathrm{~mm}$ & The maximum diameter of a bullet \\
\hline Bullet weight & $4.1 \mathrm{~g}$ & Weight of a bullet \\
\hline Bullet speed & $915 \mathrm{~m} / \mathrm{s}$ & Bullet speed at a firing point \\
\hline Drag coefficient & 0.262 & Drag coefficient of an arm with a bullet \\
\hline Level of firing line & $0.2 \mathrm{~m}$ & Distance between a firing point level and the ground level \\
\hline Height of a line of sight & $0.030 \mathrm{~m}$ & Height of a line of sight at a firing point \\
\hline $\begin{array}{l}\text { Maximum point blank range } \\
\text { (MPBR) }\end{array}$ & $25 \mathrm{~m}$ & $\begin{array}{c}\text { Horizontal distance in which a line of sight coincides with a point of impact (POI) at the } \\
\text { first time }\end{array}$ \\
\hline Actual zero distance & $250 \mathrm{~m}$ & $\begin{array}{c}\text { Horizontal distance in which a line of sight coincides with a point of impact (POI) at } \\
\text { actual distance }\end{array}$ \\
\hline Targe & $250 \mathrm{~m}$ & Horizontal distance between a firing point and a target \\
\hline Target level & $1.5 \mathrm{~m}$ & Distance between the top and bottom of a target \\
\hline Standard firing angle & $1.121^{\circ}$ & $\begin{array}{c}\text { Angle of a bullet vector with the horizon at a firing point (the specification of } 00 \text { Firing } \\
\text { Range) }\end{array}$ \\
\hline Atmospheric temperature & $15^{\circ} \mathrm{C}$ & $\begin{array}{l}\text { Atmospheric temperature acting on firing range (the standard atmospheric } \\
\text { temperature) }\end{array}$ \\
\hline Atmospheric pressure & 1013.25 mbar & Atmospheric pressure acting on firing range (the standard atmospheric pressure) \\
\hline Atmospheric density & $1.225 \mathrm{~kg} / \mathrm{m}^{3}$ & Atmospheric density acting on firing range (the standard atmospheric density) \\
\hline Gravitational acceleration & $9.807 \mathrm{~m} / \mathrm{s}^{2}$ & $\begin{array}{c}\text { Gravitational acceleration acting on firing range (the standard gravitational } \\
\text { acceleration) }\end{array}$ \\
\hline Time interval & $0.005 \mathrm{sec}$ & Unit time interval for calculation of a bullet trajectory \\
\hline
\end{tabular}

error that resulted from the accuracy of small arm. Figure 10 shows the ballistic curves distributed by a mistake of the gunner that corresponded to ten times the error of the small arm accuracy. This result shows that the ricochet range in the firing range can be significantly expanded by low accuracy and/or by a mistake of the gunner.
5.8. Supplementary Measures to Mitigate Danger Zones in Firing Ranges. If the danger zone of a firing range is considered not acceptable, a full-scale design review such as expansion of the firing range area should be considered. If a new design is impossible or very difficult, measures including (1) installation of a protective wall, (2) substitution of impact area 


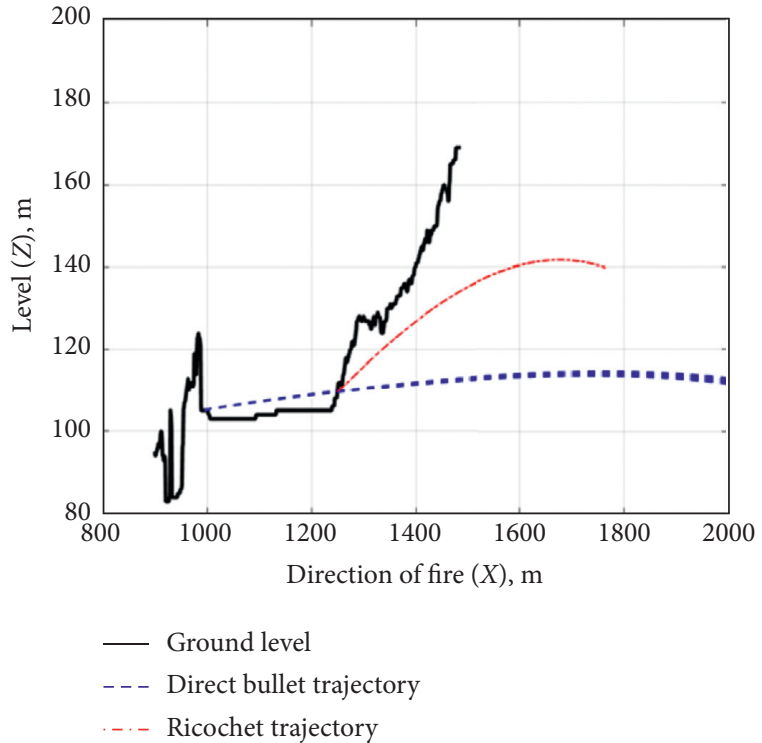

(a)

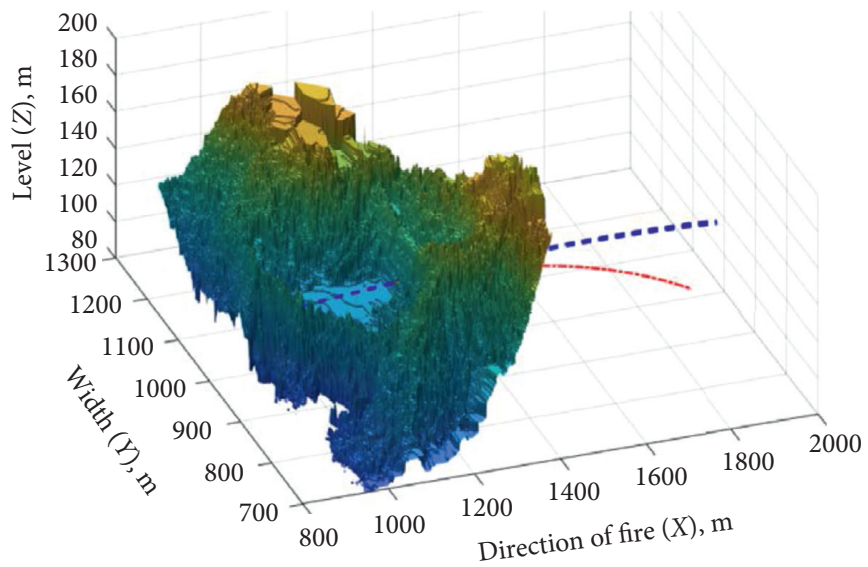

- - - Direct bullet trajectory

...- Ricochet trajectory

FIGURE 9: Bullet trajectory curves with topographic data (1000 fires of K2 rifle and K100 bullet with 4.9MOA). (a) 2D section and (b) 3D topology.

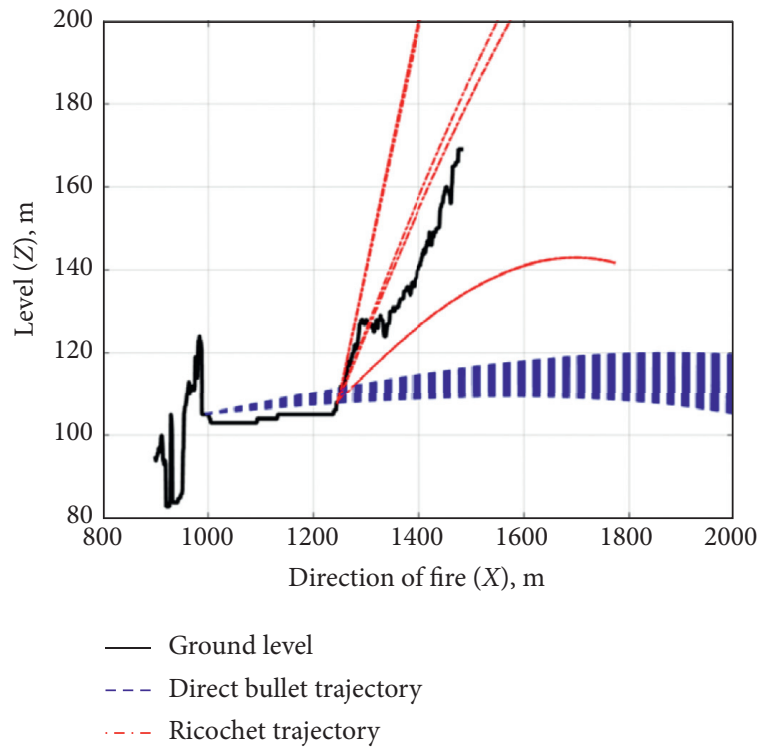

(a)

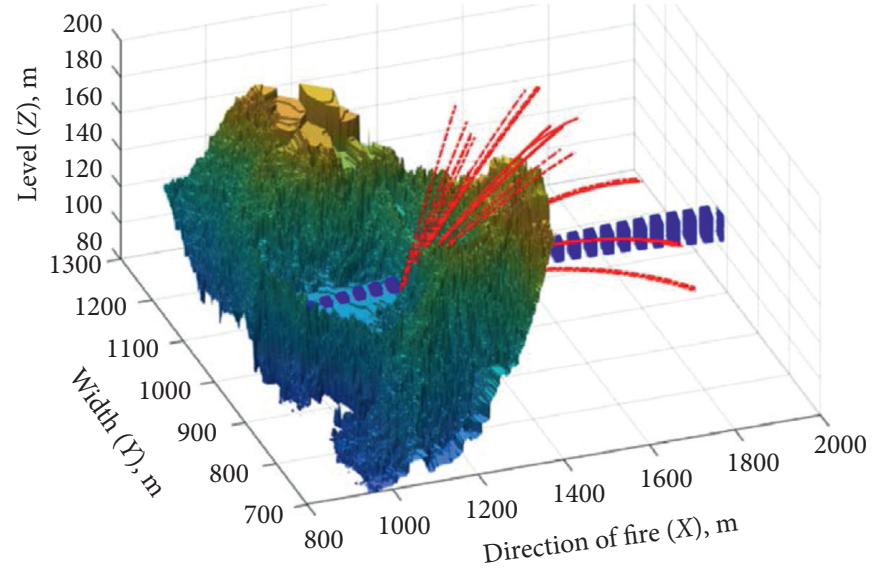

- - Direct bullet trajectory

...- Ricochet trajectory

(b)

Figure 10: Bullet trajectory curves with topographic data (1,000 fires of K2 rifle and K100 bullet with 49MOA). (a) 2D section and (b) 3D topology.

ground, (3) maintenance of a downward firing line gradient, and (4) installation of a fence to control access of personnel into the identified danger zone should be performed.

Furthermore, as well as the analyses of trajectories of direct bullet and ricochet with high-resolution numerical map, a separate team should be organized for systematic checkup of the safety of firing ranges in the Army currently in use. According to the evaluation, highly dangerous firing ranges should be closed, whereas the firing ranges that can be supplemented by additional installing safety facilities such as a protective wall should be permitted for the firing exercise. Furthermore, such measures should be addressed in the firing range installation guidelines and applied as essential matters to review before securing firing range sites.

\section{Conclusion}

To decrease the accident rate in small arm firing ranges, a methodology to determine the danger zones in firing ranges caused by direct bullets or ricochets during firing exercises 
was presented. To end this, numerical simulation analyses were performed using the actual terrain data of a firing range surveyed by a drone. According to the MCS results, the danger zone of the firing range was identified by schematizing the trajectories of the direct bullets and ricochets. The major findings in this study are summarized as follows:

(1) To address actual terrain of the firing range in determining the danger zones, three-dimensional numerical terrain data were acquired by the aerial photographs taken by a drone through a process of image matching. As the trees on the photographs were recognized as the terrain, an altitude error corresponding to the difference in the actual ground level and the height of trees may occur. Also, as a grid of $1 \mathrm{~m}$ interval was used in each direction, there was a limitation in precision. In future studies, trees and actual ground can be distinguished by carrying out an aerial survey utilizing a LIDAR sensor and errors can be minimized using denser numerical terrain data closer to the actual terrain.

(2) The specification of the small arm actually is used and the properties of the ammunition type were addressed. However, in the present study, the material of terrain was assumed as sand.

(3) As a result of three-dimensional simulation analysis with the actual terrain data, the safety of the current firing range was verified by the limited danger zone of OO Firing Range estimated using the weapon accuracy of K2 rifle with K100 ammunition. This was because, in the case of the terrain of OO Firing Range, the sides and front of the firing path are surrounded by mountainous areas. Due to the topographic advantage of the firing range, the danger zone can be significantly reduced.

(4) Meanwhile, the danger zone of OO Firing Range considering a human error by mistakes of the gunner, which was estimated by 10 times the error that resulted from the small arm accuracy, was greatly expanded. In this case, installation of safety facilities such as a protective wall is required. This result indirectly indicates that the error range caused by mistakes of the gunner may be a detrimental factor in determining safety zones in a firing range.

(5) In the future study, further numerical analyses are required considering other types of weapon, ammunition, and terrain properties. Furthermore, those results of the numerical analyses need to be compared with verifiable experiments on actual firing ranges.

In addition to engineering determination on safety zone (or danger zone) of firing range, measures to prevent safety accidents are important: to organize a separate team for systematic checkup of safety in Army firing ranges, to perform safety checkup of the identified danger zones in each firing range in use by the Army, and to install safety facilities such as a protective wall when necessary. Furthermore, such measures should be addressed in the firing range installation guidelines and applied as essential matters to review before securing firing range sites.

In the future, the methodology of the present study can be used as engineering evidence to determine safety of danger zone in firing ranges and to reinforce vulnerable firing ranges according to the results of the numerical analyses.

\section{Data Availability}

For security reasons, the entire data of OO Firing Range cannot be provided.

\section{Conflicts of Interest}

The authors declare that there are no conflicts of interest.

\section{Acknowledgments}

This work was supported by the 2020 research fund of Korea Military Academy (Hwarangdae Research Institute). The ROKA Nuclear.WMD Protection Research Center at Korea Military Academy is gratefully acknowledged for providing the financial support that made this study possible.

\section{References}

[1] SBS News, 2020, in Korean, https://news.sbs.co.kr/news/ endPage.do?news_id=N1004426906.

[2] BBC News, 2020, https://www.bbc.com/news/uk-walessouth-west-wales-17959351/.

[3] The Guardian, 2019, https://www.theguardian.com/uk-news/ 2017/jun/15/soldier-dies-after-incident-at-tank-firing-rangein-pembrokeshire/.

[4] ArmyTimes, 2019, https://www.armytimes.com/news/yourarmy/2019/04/01/alaska-soldier-killed-in-live-fire-trainingaccident/.

[5] United States Forces Korea, 2019, https://www.usfk.mil/ Media/Press-Releases/Article/1603772/new-safety-featurescertified-on-rodriguez-live-fire-complex/.

[6] B. Schram, R. Orr, T. Rigby, and R. Pope, "An analysis of reported dangerous incidents, exposures, and near misses amongst army soldiers," International Journal of Environmental Research and Public Health, vol. 15, no. 8, p. 1605, 2018.

[7] Republic of Korea Army, Standard for Installation of Training Center, Training Reference, Republic of Korea Army, South Korea, in Korean, 2008.

[8] Republic of Korea Army, Establishment of Safety Standards for Firing Range by Type of Weapon and Ammunition, Republic of Korea Army, South Korea, in Korean, 2018.

[9] D. E. Carlucci, D. E. Carlucci, and S. S. Jacobson, Ballistics: Theory and Design of Guns and Ammunition, CRC Press, Boca Raton, FL, USA, 2nd edition, 2013.

[10] H. J. Lee, Gun and Ballistics, Chungmungak Press, Seoul, South Korea, in Korean, 2001.

[11] H. J. Lee, Weapon Engineering, Chungmungak Press, Seoul, South Korea, in Korean, 2005.

[12] G. Birkhoff, G. Birkhoff, W. Bleick, E. Handler, F. Murnaghan, and T. Smith, "Ricochet off water (AMP memorandum)," 1944. 
[13] Department of the Army Pamphlet 385-63, Range Safety, Headquarters Department of the Army (U.S. Army), Washington DC, USA, 2003.

[14] DJI (Phantom3 Advanced), 2019, https://www.dji.com/kr/ support/product/phantom-3-adv/.

[15] Pix4D, 2019, https://www.pix4d.com/product/pix4dcapture/.

[16] Pix4D, 2019, https://www.pix4d.com/product/pix4dmapperphotogrammetry-software/. 